\title{
OPTIMASI KONDISI UNTUK RENDEMEN HASIL EKSTRAKSI KULIT MANGGIS (Garcinia mangostana L.) Optimization of Conditions for Yield Extraction of Mangosteen Pericarp (Garcinia mangostana L.)
}

\author{
Akhmad Endang Zainal Hasan ${ }^{1,2 *}$, Husain Nashrianto ${ }^{1}$, Rani Novia Juhaeni ${ }^{1}$ \\ ${ }^{1}$ Departemen Farmasi, Universitas Pakuan, Jalan Raya Pakuan, Bogor, Jawa Barat \\ ${ }^{2}$ Departemen Biokimia, Institut Pertanian Bogor, Kampus IPB Darmaga, Bogor, Jawa \\ Barat
}

\begin{abstract}
The aim of this study is to determine the levels of yield extract of mangosteen pericarp extracted using Response Surface Methodology (RSM) Central Composite Design (CCD) with various concentrations of ethanol (in the range of 45 to $96 \%$ ) and duration of microwave heating (in the range 5.8 to $34.1^{\circ} \mathrm{C}$ ) or Microwave Assisted Extraction (MAE). The yield extract was calculated as percentage to the weight of origin. The results showed that optimum extraction conditions for yield extract were at ethanol concentration of $70 \%$ and heating time of 31.5 minutes which resulted in yield extract of $19.45 \%$. More over, under these conditions resulted yield of $19.83 \%$. The yield extract equation of mangosteen pericarp is $Y=-73,7883+0,5293 X_{1}+2,4230 X_{2}-0,0084 X_{1}{ }^{2}-0,00173 X_{2}{ }^{2}$, where $X_{1}$ is heating time and $X_{2}$ is ethanol concentration in water as solvent.
\end{abstract}

Key words : Optimization, Mangosteen, RSM CCD, MAE, yield

\section{PENDAHULUAN}

Upaya untuk mencari kondisi optimum dari suatu penelitian menggunakan RSM pertama kali dikemukakan oleh Box dan Wilson pada tahun 1951 (Harvey 2000). Dalam rancangan ini digunakan sistem peubah secara beragam. Peubah dan taraf yang digunakan dalam RSM merupakan komponen yang efektif dalam menentukan kondisi optimum tersebut. Dalam prosesnya RSM ini akan menghasilkan model matematika akurat menggambarkan proses secara keseluruhan (Harvey 2000). Menurut Lee (2002) metode ini telah berhasil digunakan dalam rangka mengoptimalkan standar formulasi yang akan digunakan dan sistem operasi yang akan dilakukan. RSM menawarkan keuntungan yang lebih baik dan memberikan pengurangan yang nyata dalam jumlah perlakuan, sehingga menghemat waktu dan bahan yang digunakan. Oleh karena itu langkah awal dalam penerapan RSM adalah menemukan pendekatan yang cocok untuk hubungan fungsional yang benar antara respon dan peubah secara tunggal. Pada sebuah model regresi biasanya digunakan untuk melihat respon sebagai persamaan matematika dari peubah terus menerus dan estimasi parameter model terbaik yang disampaikan (Montgomery, 1997). RSM CCD adalah salah satu pendekatan yang digunakan untuk membangun model orde kedua respon, karena kemampuan RSM CCD yang dapat dijalankan secara berurutan. Pada bagian pertama memperkirakan pengaruh linear dan interaksi dua peubah, sedangkan bagian kedua memperkirakan pengaruh kelengkungan. Jika data dari bagian pertama menunjukkan tidak adanya pengaruh kelengkungan yang nyata maka bagian kedua tidak diperlukan lagi (Montgomery, 1997).

MAE adalah metode ekstraksi yang relatif baru. Metode ekstraksi ini menggunakan energi gelombang mikro 
untuk memanaskan suatu pelarut yang kontak dengan ekstrak. Pemanasan cepat dan seragam terhadap ekstrak dan pelarut menjadikan teknik ekstraksi ini secara nyata lebih efisien dibandingkan metode tradisional dan akan mengurangi biaya operasional (Hemwimon et al. 2007, Thostenson dan Chou 1999, Trusheva et al. 2009). Pada metode ini terdapat pengaturan temperatur yang akurat, sehingga dapat mempertahankan suhu yang ditentukan (Thostenson dan Chou, 1999). Menurut Amstrong (1999), ekstraksi dengan bantuan gelombang mikro merupakan proses ekstraksi yang memanfaatkan energi yang ditimbulkan oleh gelombang mikro dengan frekuensi $2450 \mathrm{MHz}$.

Manggis (Garcinia mangostana L.) merupakan tanaman tropis yang dapat dimanfaatkan untuk tujuan pengobatan, sehingga dapat dikembangkan sebagai kandidat obat. Menurut Hyene (1987), kulit manggis dapat dimanfaatkan sebagai peluruh haid, obat sariawan, penurun panas, pengelat (astringen) dan obat disentri. Menurut Geissman (1962), senyawa flavonoid memperlihatkan aktivitas sebagai antifungi, diuretik, antihistamin, antihipertensi, insektisida, bakterisida dan antivirus. Menurut Suksamrarn et al. (2003), manfaat kulit manggis tersebut disebabkan oleh kandungan flavonoid epikatekin, antosianin serta senyawa turunan xanton, diantaranya yaitu $\alpha$-mangostin, $\quad \beta$-mangostin, $\quad \gamma$ mangostin, mangostanol dan gartanin. Umumnya flavonoid tidak dapat larut dalam air, sehingga diperlukan pelarut organik lain yang dapat melarutkan flavonoid dalam proses ekstraksi. Menurut $\mathrm{Xu}$ et al. (2005), untuk mencari kondisi optimum dalam ekstraksi flavonoid suatu bahan dapat menggunakan empat peubah, yaitu konsentrasi pelarut, tempertur, nisbah bahan baku-pelarut dan waktu ekstraksi. Penggunaan pelarut organik menjadi salah satu pilihan yang dapat dipertimbangkan dalam upaya mengurangi besarnya biaya ekstraksi.

Tujuan penelitian ini adalah menentukan kondisi optimum dari konsentrasi etanol dan waktu pemanasan gelombang mikro untuk rendemen hasil ekstraksi kulit manggis.

\section{BAHAN DAN METODE Alat dan Bahan}

Alat yang digunakan antara lain microwave (frekuensi $2450 \mathrm{KHz}$ dengan daya 800 Watt), rotary evaporator, dan shaker orbital. Bahan yang digunakan antara lain: kulit manggis asal Leuwiliang, Bogor, Jawa Barat, etanol dalam air sebagai pelarut.

\section{Metode \\ Pembuatan Serbuk Simplisia Kulit Manggis}

Kulit manggis dibersihkan, kemudian dicuci dan ditiriskan, lalu dirajang dengan ukuran $0,5 \mathrm{~cm}$ lalu dikeringkan. Setelah itu dibersihkan kembali dari kotoran, diserbukkan dan diayak dengan 40 mesh. Serbuk simplisia kulit buah manggis disimpan dalam wadah tertutup.

\section{Penetapan Kadar Air}

Pemeriksaan kadar air simplisia dilakukan dengan menggunakan Moisture Balance dengan dua kali ulangan. Setiap 1 g sampel dimasukkan ke dalam alat yang telah disiapkan, pada suhu $105^{\circ} \mathrm{C}$ selama 10 menit. Kemudian dicatat kadar yang tertera pada Moisture Balance. Kadar air simplisia tidak boleh lebih dari 5\% (DepKes RI, 1994).

\section{Penetapan Kadar Abu}

Serbuk simplisia ditimbang sebanyak 2 g lalu dimasukkan ke dalam "krus platini" yang telah dipijarkan dan ditera, ratakan, lalu dipijarkan kembali 
hingga menjadi arang dan habis, kemudian didinginkan dan dilakukan penimbangan krus (BSN, 2005).

\section{Ekstraksi Kulit Manggis}

Ekstraksi dilakukan menggunakan metode Jang et al. (2009) yang dimodifikasi. Serbuk simplisia sebanyak 30 $\mathrm{g}$ dimasukkan ke dalam Erlenmeyer dan ditambahkan $600 \mathrm{mLl}$ etanol dengan konsentrasi sesuai perlakuan. Kemudian diekstraksi dengan cara maserasi dan pengadukan. Setelah 18 jam, serbuk simplisia dipanaskan dengan menggunakan bantuan gelombang mikro (KRIS
MICROWAVE OVEN) sesuai waktu perlakuan. Setelah itu ekstrak disaring dan filtratnya dikeringkan hingga membentuk serbuk. Rendemen diperoleh dengan menghitung persen bobot ekstrak terhadap bobot simplisia.

\section{Rancangan percobaan}

Penentuan optimasi dilakukan dengan metode Response Surface pada dua peubah (Tabel 1). Peubah perlakuan adalah waktu pemanasan dengan gelombang mikro dan konsentrasi pelarut etanol. Parameter uji untuk optimasi ekstraksi kulit manggis adalah rendemen hasil ekstraksi.

Tabel 1. Pola rancangan dalam batasan dan taraf dari dua peubah

\begin{tabular}{lccccc} 
& \multicolumn{5}{c}{ Batasan dan Taraf } \\
\cline { 2 - 6 } & $-\alpha$ & -1 & 0 & +1 & $+\alpha$ \\
\hline $\begin{array}{l}\text { Waktu pemanasan gelombang } \\
\text { mikro, menit }\end{array}$ & 5,8 & 10 & 20 & 30 & 34,1 \\
Konsentrasi pelarut etanol, \% & 45 & 52 & 70 & 88 & 96 \\
\hline
\end{tabular}

Penentuan $-\alpha$ dan $+\alpha$ dihitung berdasarkan rumus $-\alpha=-$ dan $+\alpha=-$, dengan $\mathrm{a}=$ variabel waktu sebagai level pusat, $b=$ variabel waktu sebagai level rata-rata dan $\mathrm{c}=$ varia-bel range waktu, sehingga diperoleh nilai tersebut dalam Tabel 1. Model matematika yang digunakan adalah : $\mathrm{Y}=\beta_{0}+\sum_{i=1}^{k} \beta_{\mathrm{i}} \mathrm{X}_{\mathrm{i}}+\sum_{i=1}^{k} \beta$ ${ }_{\mathrm{ii}} \mathrm{X}_{i}^{2}+\sum \sum_{i<j} \beta_{\mathrm{ij}} \mathrm{X}_{\mathrm{i}} \mathrm{X}_{\mathrm{j}}+\varepsilon_{\mathrm{ij}}$. Dengan $\mathrm{Y}=$ respon rendemen hasil, $\beta_{0}$ : tetapan, $\beta_{\mathrm{i}}, \beta_{\mathrm{ii}}$, $\beta_{\mathrm{ij}}$ : koefisien dari peubah bebas (X), X adalah peubah bebas dengan tanpa sandi (waktu $=\mathrm{X}_{1}$ taraf 10, 20 dan 30 menit; pelarut etanol $=\mathrm{X}_{2}$ taraf 52, 70 dan $88 \%$ ), dan $\varepsilon$ adalah galat.

\section{HASIL DAN PEMBAHASAN}

Simplisia kulit manggis yang digunakan dalam penelitian ini merupakan hasil pengecilan ukuran kulit manggis yang berasal dari Leuwiliang, Bogor, Jawa Barat. Sesuai dengan ketentuan DepKes RI (1994), kadar air suatu bahan harus ditentukan untuk memberikan batasan maksimal tentang besarnya kandungan air didalam bahan. Hasil penetapan kadar air serbuk simplisia diperoleh rata-rata sebesar 1,53\%, sedangkan kadar air ekstrak kulit manggis rata-rata sebesar $10,18 \%$. Hasil pengukuran tersebut telah memenuhi standar DepKes RI (1994) yaitu bahwa kadar air serbuk simplisia tidak lebih dari $5 \%$ dan standar kadar air ekstrak kental berkisar antara 10\% - 15\%. Kadar abu simplisia rata-rata sebesar $2,3 \%$. Hasil pengukuran kadar abu tersebut kurang dari 4\%, makasimplisia tersebut telah memenuhi standar kadar abu sesuai dalam SNI 01-7084-2005 (BSN, 2005). Hasil penetapan kadar air dan kadar abu menunjukkan nilai yang diperbolehkan dalam ketentuan yang ditetapkan dalam aturan yang ada, sehingga daya tahan penyimpanan simplisia relatif aman. 
Hasil ekstraksi kulit manggis dengan peubah waktu pemanasan gelombang mikro dan konsentrasi pelarut etanol disajikan pada Tabel 2. Hasil pengolahan sidik ragam dan analisis RSM dapat dilihat pada Tabel 3 dan Gambar 1.

Hasil analisis data rendemen hasil ekstraksi pengaruh waktu pemanasan gelombang mikro dan konsentrasi pelarut etanol menggunakan RSMCCD, diperoleh persamaan sebagai berikut : $\mathrm{Y}=-73,7883$ $+0,5293 X_{1}+2,4230 X_{2}-0,0084 X_{1}{ }^{1}-$ $0,00173 \quad \mathrm{X}_{2}^{2}$. Persamaan tersebut menunjukkan bahwa waktu pemanasan $\left(\mathrm{X}_{1}\right)$ dan konsentrasi pelarut etanol $\left(\mathrm{X}_{2}\right)$ berpengaruh secara nyata terhadap rendemen. Hal ini terlihat dari nilai koefisien nilai $\mathrm{X}_{1}$ dan $\mathrm{X}_{2}$ lebih besar dari nilai koefisien lainnya.
Hasil sidik ragam yang diperoleh dari $\mathrm{P}$ value pada $\mathrm{X}_{1}$ (waktu pemanasan) menghasilkan $(0,0024)<\mathrm{P}$ value $(0,05)$, dengan demikian waktu pemanasan sangat berpengaruh pada hasil rendemen. Pada $\mathrm{P}$ value pada $\mathrm{X}_{2}$ (konsentrasi pelarut) menghasilkan $(0,000)<\mathrm{P}$ value $(0,05)$, dengan demikian bahwa konsentrasi pelarut sangat berpengaruh pada hasil rendemen. Hasil pengujian untuk ketidak cocokan model dapat dilihat pada nilai $\mathrm{P}$ value lack-of-fit > 0,05, yang berarti kecocokkan model respon diterima. Hasil penelitian ini diperoleh yaitu $\mathrm{P}$ value $(0,286)>P$ value $(0,05)$. Artinya bahwa analisis RSMCCD tersebut adalah valid, artinya mampu memprediksikan respon dari data.

Tabel 2. Hasil rendemen ekstrak kulit manggis pengaruh waktu pemanasan gelombang mikro dan konsentrasi pelarut etanol

\begin{tabular}{cccc}
\hline No. & Lama pemanasan (menit) & Konsentrasi etanol, \% & Rendemen (\%) \\
\hline 1 & 10 & 88 & 10,48 \\
2 & 30 & 88 & 13,29 \\
3 & 10 & 52 & 10,00 \\
4 & 30 & 52 & 11,94 \\
5 & 5,8 & 70 & 13,38 \\
6 & 34,1 & 70 & 20,93 \\
7 & 20 & 45 & 8,54 \\
8 & 20 & 96 & 6,71 \\
9 & 20 & 70 & 17,21 \\
10 & 20 & 70 & 19,82 \\
11 & 20 & 70 & 18,42 \\
12 & 20 & 70 & 17,56 \\
13 & 20 & 70 & 18,72 \\
\hline
\end{tabular}

Tabel 3. Hasil sidik ragam rendemen hasil ekstraksi kulit manggis

\begin{tabular}{lllllll}
\hline Sumber & $\begin{array}{l}\text { Derajat } \\
\text { bebas }\end{array}$ & Estimasi & $\begin{array}{l}\text { Standar } \\
\text { Error }\end{array}$ & $\begin{array}{l}\text { Kuadrat } \\
\text { Tengah }\end{array}$ & Nilai F & Nilai P \\
\hline Regresi & 4 & 249,279 & 249,279 & 62,320 & 41,66 & 0,000 \\
$*$ Linier & 2 & 29,811 & 217,328 & 108,664 & 72,65 & 0,000
\end{tabular}




\begin{tabular}{lllllll} 
*Kuadratik & 2 & 219,468 & 219,468 & 109,734 & 73,36 & 0,000 \\
Sisa Kesalahan & 8 & 11,966 & 11,966 & 1,496 & & \\
*Lack-of-fit & 4 & 7,740 & 7,740 & 1,935 & 1,83 & 0,286 \\
*Kesalahan murni & 4 & 4,226 & 4,226 & 1,057 & & \\
Total & 12 & 261,246 & & & & \\
\hline $\mathrm{R}^{2}=95,4 \%$ &
\end{tabular}

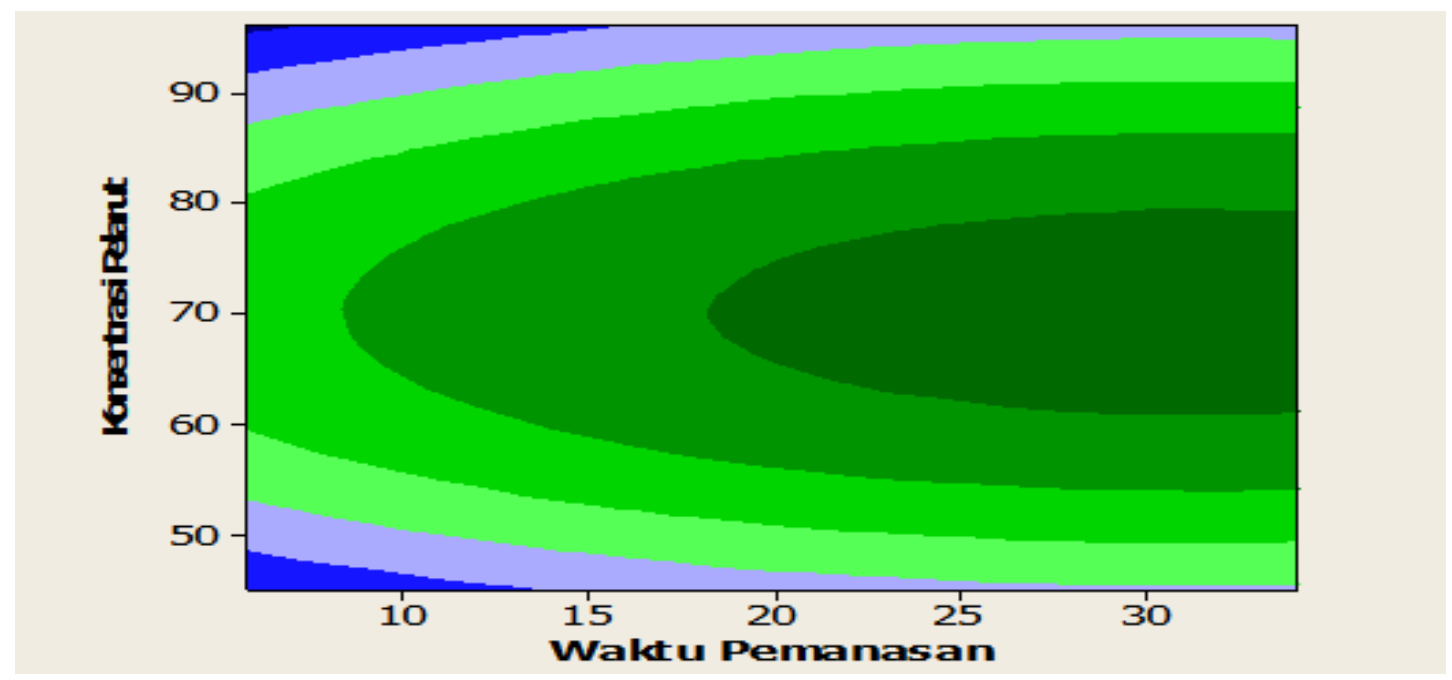

Gambar 1. Respon permukaan rendemen hasil ekstraksi kulit manggis akibat pengaruh waktu pemanasan gelombang mikro dan konsentrasi pelarut etanol

Hasil perhitungan statistik menunjukkan bahwa $\mathrm{R}^{2}=93,1 \%$, nilai ini menunjukkan bahwa besarnya pengaruh faktor lamanya waktu pemanasan dan konsentrasi etanol sedangkan 6,9\% merupakan pengaruh dari faktor-faktor di luar perlakuan yang diamati dalam penelitian ini. Analisis RSM ini sesuai dengan yang dijelaskan oleh Box dan Wilson (1951), RSM merupakan cara yang efektif untukmencari kondisi optimum dengan melihat sistem respon ketika taraf dari faktor-faktor yang terlibat berubah (Harvey, 2000). Selain itu, RSM akan menghasilkan model matematika yang akurat dalam menggambarkan proses secara keseluruhan.

Berdasarkan Gambar tersebut, bahwa makin tinggikonsentrasi dan makin lama waktu ekstraksi akan makin tinggi hasil rendemen. Namun pada konsentrasi $88 \%-96 \%$ mengalami penurunan disebabkan perbedaan kepolaran dalam menarik suatu senyawa glikosida flavonoid yang bersifat polar dan berakibat penurunan pada hasil rendemen. Hal ini seperti prinsip like dissolves like bahwa senyawa yang bersifat polar akan mudah larut dalam pelarut polar, sedangkan senyawa nonpolar akan mudah larut dalam pelarut nonpolar. Perbedaan rendemen ini disebabkan antara lain karena perbedaan kemampuan masing-masing cairan penyari dalam proses ektraksi yaitu konsentrasi etanol disertai dengan lamanya waktu ekstraksi untuk memperoleh zat aktif yang terkandung dalam simplisia tersebut dan kelarutan zat aktif dalam cairan penyari yang berbeda. Dalam Gambar tersebut ditunjukkan bahwa persamaan RSM ini mempunyai nilai maksimum pada waktu pemanasan \pm 30 menit dengan konsentrasi etanol $70 \%$. Terlihat bahwa nilai rendemen ekstraksi 
menunjukkan terjadi penurunan pada konsentrasi etanol lebih besar dari $70 \%$. Dengan menggunakan D-optimally (Saputera 2008) diperoleh hasil optimasi rendemen sebesar $19,45 \%$ pada waktu 31,5 menit dengan konsentrasi etanol $70 \%$. Dengan etanol $70 \%$ ternyata sangat efektif dalam menghasilkan jumlah bahan aktif dengan skala kecil pengotor yang turut ke dalam cairan ekstrak (Harborne 1987).

Pada proses pembuatan ekstrak optimum dilakukan seperti pembuatan ekstrak sebelumnya. Hasil yang diperoleh adalah rendemen ekstrak sebesar $19,83 \%$. Nilai bias antara hasil verifikasi sebesar $1,9 \%$ atau rendemen yang diperoleh lebih banyak dibandingkan dengan hasil proyeksi dari model persamaan. Pada kondisi optimum ini kadar total flavonoid sebesar $11,42 \%$ (Hasan et al. 2013)

\section{KESIMPULAN}

Rendemen optimum hasil ekstraksi kulit manggis diproyeksikan sebesar 19,45\% dicapai pada konsentrasi pelarut etanol $70 \%$ dengan waktu pemanasan gelombang mikro 31,5 menit pada model persamaan $\mathrm{Y}=-73,7883+0,5293 \mathrm{X}_{1}+$ $2,4230 \mathrm{X}_{2}-0,0084 \mathrm{X}_{1}{ }^{2}-0,00173 \mathrm{X}_{2}{ }^{2}$. Hasil verifikasi kondisi optimum diperoleh rendemen sebesar 19,83\%.

\section{DAFTAR PUSTAKA}

Amstrong, AD. 1999. MicrowaveAssisted Extraction for The Isolation of Trace Systemic Fungicides From Woody Plant Material. [Doctor dissertation]. Virginia Polytechnic Institute and state University.

Box GEP, Wilson KB. 1951. "On the Experimental Attainment of
Optimum Conditions." J Royal Stat Soc B, 13:1-45.

[BSN] Badan Standarisasi Nasional. SNI 01-7084-2005. Jakarta

DepKes RI. 1994. Lampiran Keputusan Menteri Kesehatan RI No. 661/IMENKES/SK/VII/ 1994 tentang Persyaratan Obat Tradisional. Jakarta

Geissman, T. A.1962. The Chemistry of Flavonoid Compounds. Pergamon Press, Inc : New York. 541 hlm.

Hasan AEZ, H Nashrianto, RN Juhaeni. 2013. Optimization of Extraction of Flavonoids from the Mangosteen (Garcinia mangostana L.). EJFA. Akan Terbit.

Harborne, J.B. 1987. Metode Fitokimia: Penentuan Cara Modern Menganalisis Tumbuhan (Padmawinata $\mathrm{K}$, penerjemah). ITB: Bandung:84-94.

Harvey D. 2000. Modern Analytical Chemistry. New York: McGraw Hill.

Hemwimon S. P Pavasant, Shotipruk A. 2007. Microwave yang dibantu ekstraksi anthraquinones antisoksidan dari akar Miranda citrifolia. Pemisahan Technol Pemurnian, 54:44-50.

Heyne, K. 1987. Tumbuhan Berguna Indonesia. Jilid 3. Departemen Kehutanan: Jakarta.

Jang MJ, SR Sheu, CC Wang, YL Yeh, KH Sung. 2009. Optimization analysis of the experimental parameters on the extraction process of propolis. Proceedings of the International Multi Conference of Engineers and 
Computer Scientists. II, IMECS.

Lee, H. J. 2002. Designing of an electrolysis desalination plant. Desalination.142:267-286.

Montgomery, D. C. 1997. Response Surface Methods and Other

Wiley \& Sons, New York, USA:427-510.

Saputera. 2008. Karakterisasi Biji Kamandrah (Croton tiglium L.) dan Pengembangan Teknologi Proses Ekstrak Terstandar sebagai Bahan Laksatif. [disertasi]. Sekolah Pascasarjana, Institut Pertanian Bogor.

Suksamrarn, S., N.Suwannapoch, P. Ratananukul, N. Aroonlerk, and A.

propolis: a preliminary study. Chem Center, 1(13): 1-4.

Thostenson E.T dan T.W. Chou. 1999. Microwave pengolahaan: fundamental dan aplikasi . $J$ Komposit: Bagian A. 30:1055-1071.

Trusheva B, D Trunkova, V Bankova. 2006. Preliminary communication, Different extraction methods of biologically active components from
Hongkong. 1295-1299.

Approaches to Process

Optimization. In: Design and analysis of experiments. $4^{\text {th }}$ ed. John

Suksamrarn. 2003. Antimycrobacterial activity of prenylated xanthones from the fruits of Garcinia mangostana. Chem Pharm Bull. 51(7):857-859.

Wijayakusuma H., S. Dalimartha., dan A. S. Wirian., 1992. Tanaman Berkhasiat Obat di Indonesia. Pustaka Kartini, Jakarta. Hlm 112113.

Xu Y, Zhang R, Fu H. 2005. Studies on the optimal process to extract flavonoids from red-raspberry fruits. J Nat Sci 3:43-46.

Yoshihiro. 1997. Pregnan glycosides from Sansevieria Trifasciata. Phytochemistry 44:107-111. 